\title{
Design of Monopole Antenna Loaded with Split Ring Resonator for Dual Band Operation
}

\author{
R.Balamurugan ${ }^{1}$, U.Surendar ${ }^{2}$ \\ Assistant Professor, Department of ECE, K.Ramakrishnan College of Engineering, Trichy, India ${ }^{1,2}$
}

\begin{abstract}
This paper introduces the ultra-wide band split ring monopole antenna for wireless application. The overall size of the antenna $22 \mathrm{~mm} \times 19 \mathrm{~mm} \times 1.6 \mathrm{~mm}$.It covers the impedance bandwidth of $2000 \mathrm{MHz}$.A monopole antenna with CSSR-based ground plane for wireless application. The proposed antenna offers gain of $3.5 \mathrm{~dB}$ and directivity for the frequencies $3.45 \mathrm{GHz}$ and $5.4 \mathrm{GHz}$. Constantly maintains similar radiation pattern for the maximum frequencies.
\end{abstract}

Keywords: Split Ring Monopole Antenna, Bandwidth, Gain, Radiation Pattern, CSSR-Based Ground Plane

\section{INTRODUCTION}

In a transceiver system the antenna elements are arranged sequentially coupled with an electrical system. The elements in the antenna structure act as bidirectional for radio waves in either all directional in nature or specific directions with maximum gain and directivity. The major antenna elements are reflectors, horn, parasitic elements it provide the direction for the radio waves to achieve the preferable radiation pattern and enter into the beam. [5]

In radiofrequency domain, an antenna elements are computing between radiofrequency waves spreading through free space in addition to the current moving in metallic conductors, utilize with a transceiver. While it transmits the radio frequency waves extracts current to the antenna's ends, and the antenna spreads the energy in the form of current as EM waves. while receiving the antenna obstruct the small quantity of radiofrequency waves and make it as electric current at one end and its amplified for further processing[6].

Micro strip patch antennas are constructed using a patch mount on the substrate over a ground plane. The major applications domains like satellite communication, avionics, smart mobile phones, used the patch antenna to give maximum performance. Patch antennas are designed simply with the characteristics of low profile and costless.[6]

These micro strip patch antenna elements were feeding using major methods were listed as follow as micro strip line, coaxial probe, aperture coupling and proximity coupling. For an efficient communication either in wired mode or wireless mode the bandwidth is obtained maximum amount of data sent through one end to another end for a specific time. By increasing the thickness of the radiating patch substrate, the aperture size through which the fields are radiating to the space can be enhanced leading to easier impedance matching of antenna bandwidth enhancement.

A CPW fed ring shaped antenna is proposed in a compact size to work for real time LAN's[6] Miniaturization through Negative material effects is proposed in[6], where the monopole antenna proposed operated at WLAN and Wi-max frequencies. The proposed antenna had a very compact size due to achieving meta-material effect by loading the antenna with ELC meta-material resonator. Similar better impedance matching was achieved to make the antenna resonate efficiently in [7].

A SRR loaded material antenna is proposed for RF-ID applications. Similarly in [8] a CPW fed antenna provided a broadside array beam suitable for Wi-Max applications. An optimized coupling network was designed using optimization techniques like ANN[7]. Optimized coupler and power divider was designed using SIW which helped in achieving an optimized response at desired wireless application.[10][1][2].An optimized miniaturized filter using stepped impedance resonators was proposed in [4]achieve higher selectivity for resonating at the desired frequency. Current innovations on high frequency applications like millimetre wave applications, were discussed in [5] to have a broader view in designing antennas.[5], a compact patch antenna was designed for ISM band application[3].

\section{PROPOSED ANTENNA}

The proposed antenna has maintains constantly similar radiation pattern for all operating frequencies has the gain of 3.5 $\mathrm{dB}$. It has a dimension of $22 * 19 * 1.6 \mathrm{~mm}^{\wedge} 3$ and the bandwidth range is from $200 \mathrm{MHz}$. To achieve the parameters more efficiency, we are proposing the reconfigurable antenna with RF switches. 
Vol. 8, Issue 5, May 2019

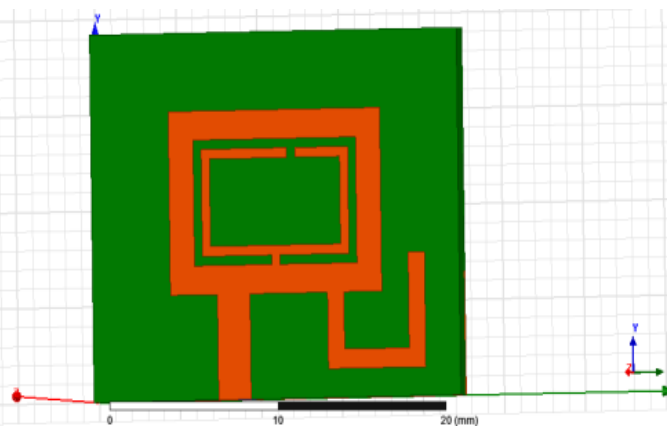

Fig.1 Top view of the proposed structure

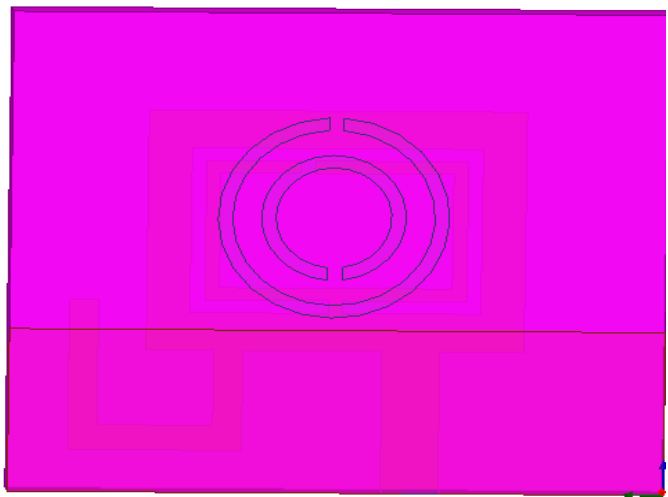

Fig.2 Bottom view of the proposed structure.

From the above stimulated output, it covers an impedance bandwidth of 5910MHz (4.04-9.95GHz.) The patch antenna is modified into square ring shaped patch antenna which is included with uniform impedance resonator which helped in the resonance at the desired frequency. The dimensions of the antenna are modified in such a way that the designed antenna is applicable for real-time mobile applications. The modified ring shaped patch used in the design is helpful in reducing the patch antenna's dimension which can be used for mobile real-time applications.

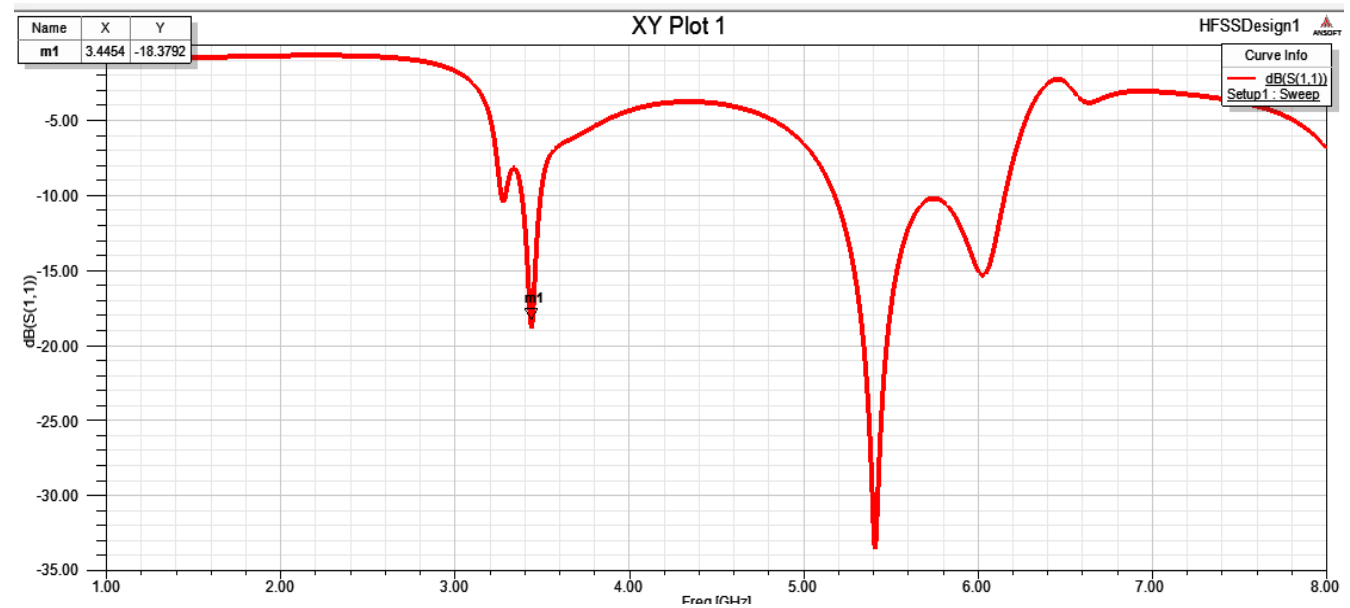

Fig 3: Stimulated Result of the proposed structure.

III. DESIGN EQUATION

\subsection{Effective Dielectric Constant:}

$$
\varepsilon_{\text {eff }}=\frac{\varepsilon_{r}+1}{2}+\frac{\varepsilon_{r}-1}{2}\left[1+12 \frac{h}{W}\right]^{-\frac{1}{2}}
$$

Where $\mathrm{W}$ is the Width of the Patch

$\varepsilon_{\mathrm{r}}$ shows relative Permittivity of the dielectric substrate 


\subsection{Effective Length}

Where, $\mathrm{f} 0$ is the Resonance Frequency

$$
\Delta \mathrm{L}=0.412 \mathrm{~h} \frac{\left(\varepsilon_{e f f}+0.3\right)\left(\frac{W}{h}+0.264\right)}{\left(\varepsilon_{e f f}-0.258\right)\left(\frac{W}{h}+0.8\right)}
$$

C represents light speed: $3 \times 10^{8} \mathrm{~m} / \mathrm{s}$

\subsection{Actual Length of the Patch:}

$$
L=L_{\text {eff }}-2 \Delta \mathrm{L}
$$

Where, $\Delta \mathrm{L}$ is length extension

From the proposed system, the various parameters obtained are verified for its performance parameters using simulation. The calculated conventional patch antenna is modified and reduced for its size using meta-material technique by implementing the complementary split ring resonators in the ground layer of the proposed patch antenna. The meta-material is an artificial material in which the material possess artificial properties like negative refractive index, negative permeability and permittivity values.

\subsection{VSWR}

VSWR is Voltage Standing Wave Ratio is the parameter that numerically explains way of well the antenna's impedance matching parameter to the radio or transmission line is connected. For traditional antenna the Voltage Standing Wave Ratio value is 1-2.The obtained VSWR is 1.15

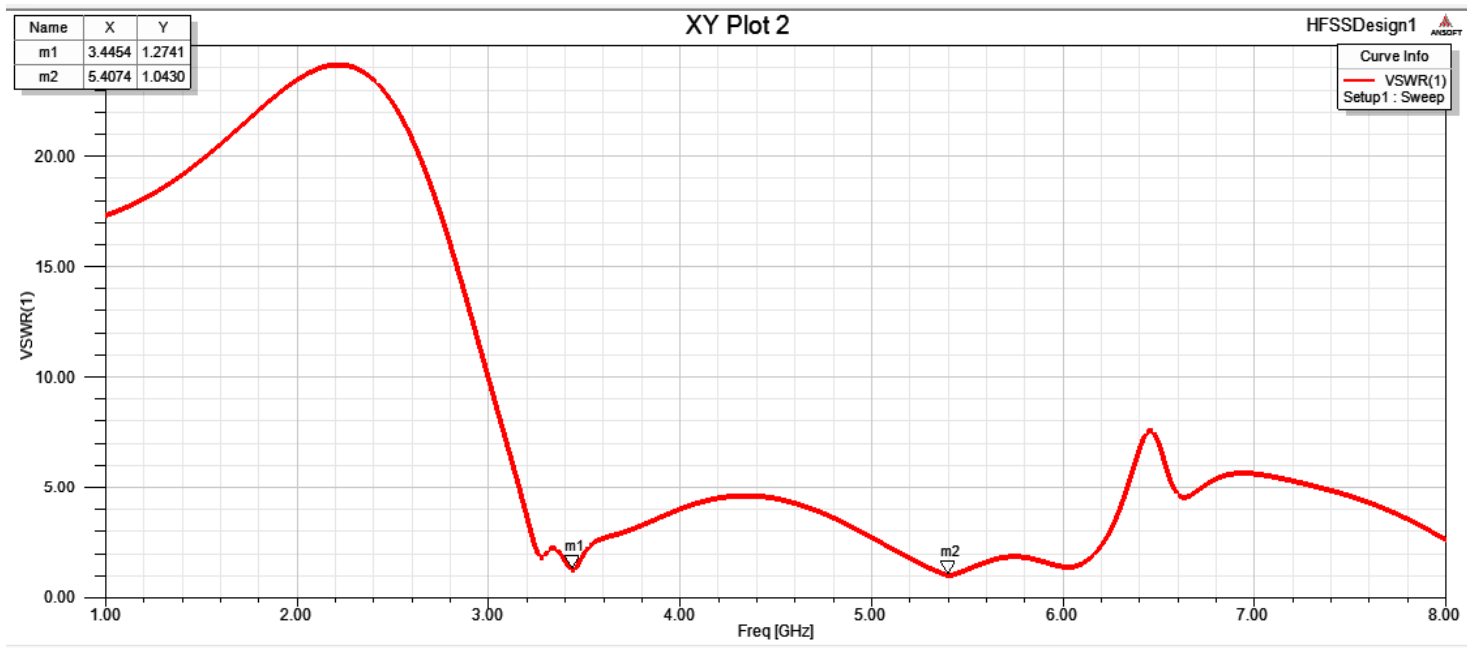

Figure 4 VSWR Plot

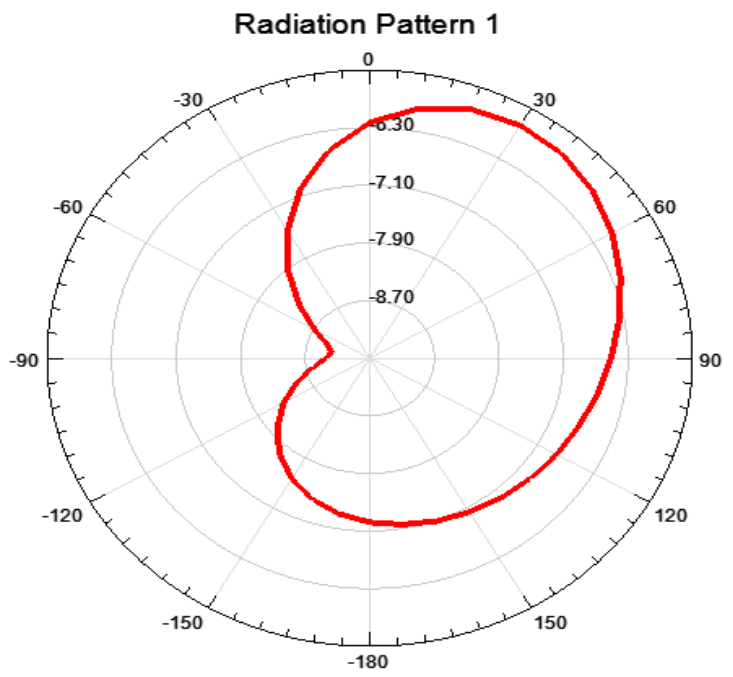

(a) 
Vol. 8, Issue 5, May 2019

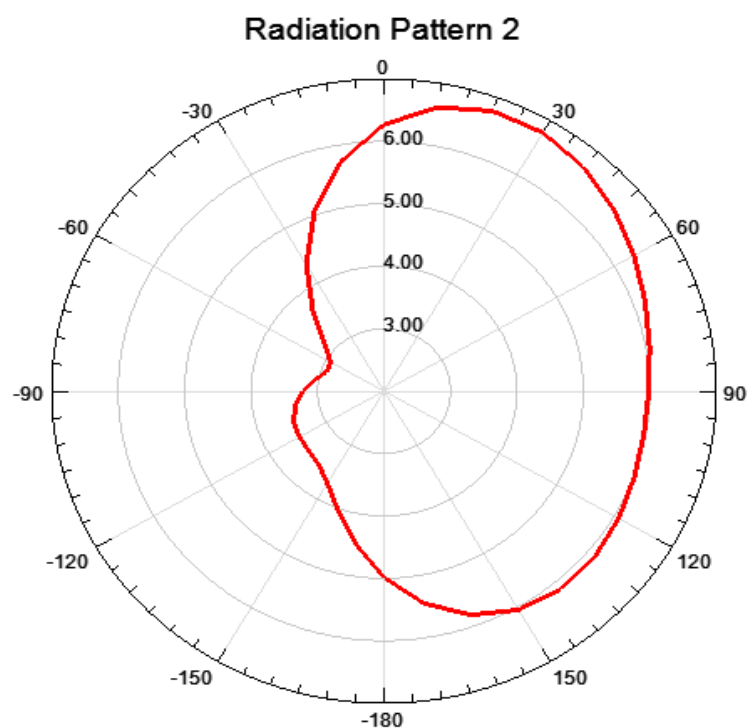

(b)

Fig-5: Radiation Patterns

\subsection{Radiation Pattern}

The radiation pattern is a mandatory parameter of antenna elements represents radiation energy in terms of graph with the distribution of radiation energy. The maximum radiation available is measured with the help of field strength. The radiation pattern obtained $\mathrm{E}$ aperture is bidirectional and the radiation pattern obtained $\mathrm{H}$ aperture is omni directional.

\subsection{Gain}

The antenna gain is important factor which improves and increase the performance factors like directivity and electrical throughput.The proposed antenna offers $2.29 \mathrm{~dB}$ and $3.72 \mathrm{~dB}$ gain for the frequencies $4.96 \mathrm{GHz}$ and $8.47 \mathrm{GHz}$ respectively.
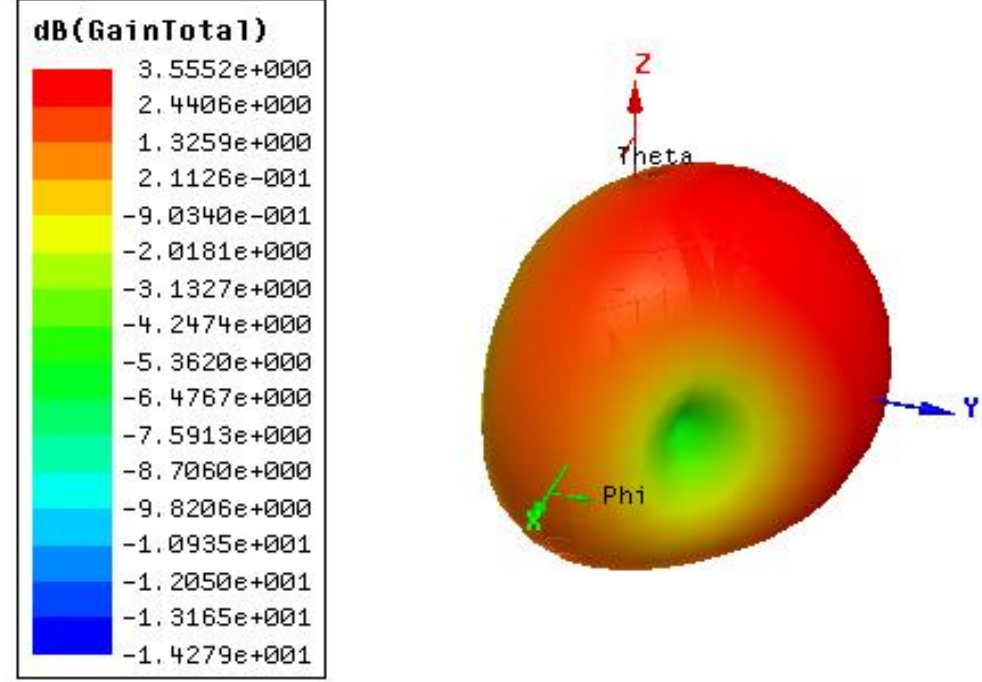

Figure 6 Antenna Gain

\section{CONCLUSION}

The proposed antenna has a compact size of $22 \mathrm{~mm} \times 19 \mathrm{~mm} \times 1.6 \mathrm{~mm}$.It covers an impedance bandwidth of $2000 \mathrm{MHZ}$ thus it is used for dual band operation. The proposed antenna has good gain and broader bandwidth. The modified antenna has size reduction when compare to split ring and ring antenna with same overall dimensions. Good radiation pattern and VSWR were obtained. Hence, the above characteristics of antenna shows that the modified patch antenna .may be a good alternative for mobile applications/ 
Vol. 8, Issue 5, May 2019

\section{REFERENCES}

[1]. Anilkumar, Murugeshwari.B, Raghavan.S, Design of Substrate Integrated Waveguide Power Divider and Parameter optimization using Neural Network, IOSR Journal of Electronics and Communication Engineering (IOSR-JECE), Vol.13, issue 1, Ver. I, PP 37-43(Jan-Feb. 2018)

[2]. Gayathri R, Maheswari M, Design And Fabrication Of Dual Band RFID Antenna Using Hybrid Coupler With CSRR, Pakistan Journal of Bio Technology, Vol.14 (1), pp. 87-89, (2017).

[3]. Monisha.S, Surendar.U, A Survey on Wearable Antenna for ISM Band Application, IOSR Journal of Electronics and Communication Engineering, pp. 49-54, (2018).

[4]. Muruganantham T, Surendar U, Balakumar A, Dual Band Bandpass Filter With Sharp Passband Resonances Using Dual-Mode SIRs, International journal of microwave applications,volume6,no.2,(March-April 2017.

[5]. Praveena.S, Murugeshwari.B, Surendar.U and Kayalvizhi.R, A Review on Antenna Design for Millimeter Wave range, IOSR Journal of Electronics and Communication Engineering, pp. 01-06, (2018

[6]. Samson Daniel.R, Design and Simulation of Multiband CPW feed Ring Shaped Antenna for Wireless Applications, International Journal of Engineering Sciences \& Research Technology, pp.549-553, (2014)

[7]. Samson Daniel.R, Pandeeswari.R, Raghavan.S,Dual-band monopole antenna loaded with ELC metamaterial resonator for WiMAX and WLAN applications, Applied Physics A, vol.124, issue18, (2018)

[8]. ThamilSelvi.N, Pandeeswari.R, and ThiruvalarSelvan.P.N, An Inset-Fed Rectangular Microstrip Patch Antenna with Multiple Split Ring Resonator Loading for WLAN and RF-ID Applications, PIER C, vol.81, pp.41 - 52, (2018)

[9]. ThamilSelvi.N, ThiruvalarSelvan.P.N, Babu. S. P. K., Pandeeswari.R, and Samson Daniel.R, A Broad-Side Coupled SRR Inspired CPW Fed Dual Band Antenna for WiMAX and Wave Applications, PIER C vol. 80, pp.221 -231, (2018)

[10]. VarikuntlaKrushnakanth, Murugeshwari.B, \&SingaraveluRaghavan, Design of a CPW Fed Substrate integrated waveguide using Frequency selective surface, 11th International Radar symposium India (IRSI'17), Bangalore, India (2017.

\section{BIOGRAPHIES}

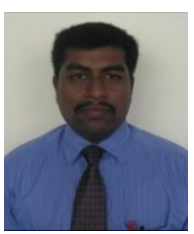

R.Balamurugan, completed Bachelors degree in Electronics and Communication Engineering and Masters VLSI Design from Anna University in 2008 and 2012 respectively. He is lifetime Member of Indian Society of Technical Education (MISTE), and field of research interest is designing Real time Embedded Systems, IOT, Wireless Communication. He has a teaching experience of 8 years. Presently working as Assistant Professor, ECE Dept. in K. Ramakrishnan College Of Engineering, Trichy.

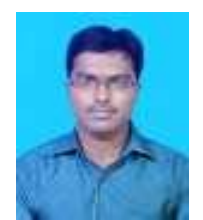

U. Surendar, completed Bachelors degree in Electronics and Communication Engineering and Masters in Communication Systems from Anna University in 2011 and 2014 respectively. He is lifetime Member of Indian Society of Technical Education (MISTE), and field of research interest is designing RF antennas and filters for advanced wireless mobile applications.. Presently working as Assistant Professor, ECE Dept. in K. Ramakrishnan College Of Engineering, Trichy, currently pursuing Ph.D. 